\title{
Transition Time: Passing the Editor Baton
}

\author{
Dorothy S. Becvar
}

Published online: 5 November 2011

(C) Springer Science+Business Media, LLC 2011

After 5 years as Editor of Contemporary Family Therapy I have decided to step down at the end of December 2011. I do so with gratitude for the unique opportunities and experiences this position has provided. And I offer my best wishes to Dr. Russell Crane, who will take over the editor duties as of January 1, 2012. I trust that he, too, will find the perspective offered by and the roles inherent in this position to be enlightening and meaningful. The following are a few closing reflections in this regard.

Most importantly, I have appreciated the opportunity to work with both scholars and reviewers from around the world. It is, of course, thanks to those who are called to do the practice and research and then share their findings that journals such as this one are able to contribute to the growth and development of the field of marital/couple and family therapy. At the same time, an equal contribution is provided by the many, many reviewers who volunteer their time and energy to the evaluation of manuscripts and the provision of feedback to authors.

The role of mentor also has been extremely significant for me. Indeed, I have felt a tremendous responsibility to help those newer to the challenge of writing publishable articles become successful authors, just as I was helped earlier in my career. Even when the final decision was to reject, I believed that the blow could be softened-for the author(s) and for me-by offering comments and suggestions that might help in future work.

In addition, it certainly has been interesting for me to consider the various articles submitted as each issue deadline has approached. Indeed, with the exception of one special issue, no theme was ever established in advance, nor did I ever solicit articles on a particular topic. And yet, most of the time I was able to infer patterns among the articles that were ready for publication. Often, as was the case with this edition, these patterns transcended international boundaries. They speak to me of current trends and the evolution of future developments in the field, which certainly is important information for all of us. For example, in this issue I have identified three patterns among the seven articles

D. S. Becvar (ه)

School of Social Work, Saint Louis University, St. Louis, MO, USA

e-mail: becvards@slu.edu 
included: a focus on the therapist; a focus on therapeutic teamwork; and a focus on connections.

Three articles are included in the first category, a focus on the therapist. First, "Learning and Living Systemic: Exploring the Personal Effects of Family Therapy Training" by Paul Rhodes, Chai Nge, Andrew Wallis, and Caroline Hunt provides qualitative findings of a study done in Australia relative to the impact of learning about and reflecting on a systems theoretical perspective. In the next article, "Clinical Intuition: A Qualitative Study of Its Use and Experience among Marriage and Family Therapists," Aaron Jeffrey and Linda Stone Fish describe findings indicating that intuition, though not well researched in the MFT field, may provide access to useful information for therapists in their work with clients. The third article in this category, "Therapist Use-of-Self Orientation Questionnaire: A Reliability and Validity Study" by Stephen Anderson, Jessica Sanderson, and Iva Košutić, offers a report on the utility of a questionnaire that measures and provides information on three different ways in which therapists may orient themselves as they work with clients or supervisees.

In the second category, a focus on therapeutic teamwork, there are two articles. The first of these, "Building Collaborative Mental Health Teams in Schools Through MFT School Certification: Initial Findings" by Kathleen Laundy, William Nelson, and Daisy Abucewicz, the history and experiences of MFTs who are now joining the ranks of mental health professionals who are attempting to ensure that the educational needs of all children are being met are described. Also in this category is "Integrated Family Assessment and Intervention Model: A Collaborative Approach to Support Multi-Challenged Families" by Ana de Melo and Madalena Alarcão. This article provides a description of a home-based program implemented in Portugal that was designed to find solutions for families in which child abuse or neglect has occurred.

The third category, a focus on connections, also includes two articles. The first, "The Relationship Between Personality and Marital Adjustment Among Distressed Married Couples Seen in Intensive Marital Therapy: An Actor-Partner Interdependence Model Analysis" was written by Joshua Knabb and Ronald Vogt. In this article the authors seek to understand the various connections between personality dimensions and marital satisfaction. Jacob Christenson, Russell Crane, Hafen McArthur, Stacy Hamilton and Bruce Schaalje authored the second article, "Predictors of Health Care Use Among Individuals Seeking Therapy for Marital and Family Problems: An Exploratory Study." Understanding and describing the connections between mind and body as evidenced in patterns of health care use by those who have requested help for problems related to their family or marriage is the theme of the final contribution to this category and this issue. It is my sincere hope that this edition, like those that have preceded it, provides useful information for the practitioners, researchers, and teachers who are the readers of this journal.

As I now officially pass on the baton, I would be remiss if I did not acknowledge the previous Editor of this journal, Bill Nichols, who recruited me for the job and provided essential and ongoing support as I learned the ropes. This was especially important during the early days of my term, before the shift to electronic submissions. My thanks as well for the excellent support provided by the Springer publication team, only one of whom I have met in person. It has been a great and rewarding adventure! 